LAWRENCE LIVERMORE NATIONAL LABORATORY

\title{
How Small Can a Launch Vehicle Be?
}

\author{
John C. Whitehead
}

\section{July 10, 2005}

$41^{\text {st }}$ AIAA/ASME/SAE/ASEE

Joint Propulsion Conference and Exhibit

Tucson, AZ

Paper Number AIAA-2005-4506

AIAA = American Institute of Aeronautics and Astronautics

ASME = American Society of Mechanical Engineers

SAE = Society of Automotive Engineers

ASEE = American Society of Engineering Education 
This document was prepared as an account of work sponsored by an agency of the United States Government. Neither the United States Government nor the University of California nor any of their employees, makes any warranty, express or implied, or assumes any legal liability or responsibility for the accuracy, completeness, or usefulness of any information, apparatus, product, or process disclosed, or represents that its use would not infringe privately owned rights. Reference herein to any specific commercial product, process, or service by trade name, trademark, manufacturer, or otherwise, does not necessarily constitute or imply its endorsement, recommendation, or favoring by the United States Government or the University of California. The views and opinions of authors expressed herein do not necessarily state or reflect those of the United States Government or the University of California, and shall not be used for advertising or product endorsement purposes. 


\title{
How Small Can a Launch Vehicle Be?
}

\author{
John C. Whitehead* \\ Lawrence Livermore National Laboratory, Livermore, CA 94551
}

\begin{abstract}
Trajectory simulations from Earth to orbit indicate comparative velocity requirements depending on vehicle size, for several propellant options. Smaller vehicles are more affected by drag, resulting in steeper trajectories that require more total velocity. Although they are technically challenging, launch vehicles smaller than 1 ton are not ruled out by the nature of ascent trajectories.
\end{abstract}

\section{Introduction}

There have been many efforts toward building ever-smaller satellites in recent years. It is therefore of interest to consider the minimum practical size for launch vehicles that can reach Earth orbit. Aerodynamic drag is more significant for smaller vehicles due to their higher ratio of drag area to mass, so trajectory analysis offers information relevant to the lower size limit.

Figure 1 shows two extreme paths to orbit, each of which has two propulsive maneuvers. ${ }^{1}$ Path A uses a horizontal launch directly into an elliptical orbit, which is circularized with a small burn. The Path B vehicle

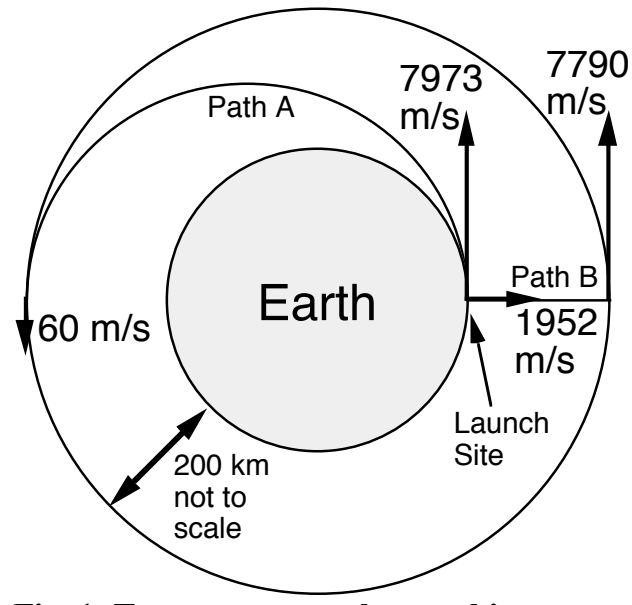

Fig. 1. Two extreme paths to orbit. launches vertically and coasts to a stop at the desired altitude above the launch site, where it needs a circularization burn equal to orbital velocity. The labeled velocities for a $200-\mathrm{km}$ orbit are based on ideal assumptions of vacuum (no drag), and impulsive velocity changes (infinite thrust).

Path A ideally requires the least $\Delta \mathrm{v}, 8033 \mathrm{~m} / \mathrm{s}$, for the same reasons that a Hohmann transfer is the most efficient means of orbit raising. The inefficient Path B needs 1.21 times this $\Delta \mathrm{v}, 9742 \mathrm{~m} / \mathrm{s}$ (the ratio peaks at 1.39 , for $2280 \mathrm{~km}$ altitude). Neither extreme is actually used, but every real path to orbit lies somewhere between Path A and Path B. A trajectory can be partly characterized by the great circle arc angle and the magnitude of its circularization burn, the two of which tend to vary oppositely.

Path A requires more time in the atmosphere than Path B. As the significance of aerodynamic drag increases, a preferred trajectory is pushed further from Path A, toward Path B. Higher acceleration (thrust-to-mass ratio) also favors steeper trajectories, to reduce the time spent in the atmosphere at high speeds.

Low acceleration requires a steep initial ascent, to align thrust and weight vectors. Gravity losses can result in a high $\Delta v$ requirement, even though such vehicles may pitch over and ultimately circularize at a large arc angle like Path A. Thus real trajectories are more than simple compromises between Path A and Path B. Detailed calculations are needed to estimate actual $\Delta \mathrm{v}$ requirements through the atmosphere with finite thrust.

\section{Trajectory Simulation}

The mathematical model was described in Ref. (1). Earth rotation and wind effects are not included. Constant thrust depletes a variable propellant quantity, followed by a coast to apogee at $200 \mathrm{~km}$ altitude. The launch angle is adjusted to obtain this altitude without steering. The required circularization $\Delta \mathrm{v}$ is added to ascent $\Delta \mathrm{v}$, obtained from the propellant mass, in order to determine the total $\Delta v$ to orbit. Starting with a set of vehicle design assumptions, the ascent propellant quantity (hence thrust duration) is varied to find the least total $\Delta \mathrm{v}$.

* PO Box 808, Mail Stop L-413, AIAA Senior Member. 
Table 1 lists the relevant fixed parameters. The drag coefficient increases at transonic speeds to triple just above Mach 1, then it settles to $50 \%$ over the low-speed value, past Mach 4. Table 2 summarizes vehicle design assumptions for all 15 cases tried. The ratios of frontal areas to launch masses are based on propellant densities, along with the assumption of a 10:1 length-to-diameter ratio. Thrust is 1.33 of launch weight for all the liquid cases, but the solid-propelled thrust-to-mass ratio varies by only a factor of 8 for each order of magnitude in vehicle mass. Large solid rocket stages are designed to have burn areas to obtain sufficient thrust. The smallest ones typically have more thrust than necessary because the exposed burn area cannot be less than the cross sectional area, i.e. an end burning grain.
Table 1. Fixed parameters for Mars calculations.

\begin{tabular}{|l|l|}
\hline Parameter & Value \\
\hline \hline Gravitational constant & $6.67 \times 10^{-11 \quad \mathrm{~N}-\mathrm{m}^{2} / \mathrm{kg}^{2}}$ \\
\hline Earth mass & $5.97 \times 10^{24} \mathrm{~kg}$ \\
\hline Earth radius & $6380 \mathrm{~km}$ \\
\hline Atmospheric density at surface & $1.225 \mathrm{~kg} / \mathrm{m}^{3}$ \\
\hline Atmosphere scale height (1/e decay) & $7.0 \mathrm{~km}$ \\
\hline Speed of sound & $300 \mathrm{~m} / \mathrm{s}$ \\
\hline Low speed drag coefficient & 0.2 \\
\hline
\end{tabular}

Table 2. Vehicle sizing assumptions for different propellants.

\begin{tabular}{|c|c|c|c|c|c|c|}
\hline \multirow{2}{*}{$\begin{array}{l}\text { Launch } \\
\text { mass, } \\
\text { tons }\end{array}$} & \multicolumn{2}{|c|}{ Oxygen-hydrogen } & \multicolumn{2}{|c|}{ Oxygen-kerosene } & \multicolumn{2}{|c|}{$\underline{\text { Solid }}$} \\
\hline & $\begin{array}{l}\text { Frontal } \\
\text { area, } \mathrm{m}^{2}\end{array}$ & $\begin{array}{l}\text { Thrust, } \\
\text { kN }\end{array}$ & $\begin{array}{l}\text { Frontal } \\
\text { area, } \mathrm{m}^{2}\end{array}$ & $\begin{array}{l}\text { Thrust, } \\
\text { kN }\end{array}$ & $\begin{array}{l}\text { Frontal } \\
\text { area, } \mathrm{m}^{2}\end{array}$ & $\begin{array}{l}\text { Thrust, } \\
\text { kN }\end{array}$ \\
\hline 0.01 & 0.021 & 0.13 & 0.011 & 0.13 & 0.0075 & 0.63 \\
\hline 0.1 & 0.10 & 1.3 & 0.05 & 1.3 & 0.035 & 5.0 \\
\hline 1.0 & 0.46 & 13 & 0.23 & 13 & 0.16 & 40 \\
\hline 10 & 2.15 & 130 & 1.08 & 130 & 0.75 & 320 \\
\hline 100 & 10.0 & 1300 & 5.0 & 1300 & 3.5 & 2500 \\
\hline
\end{tabular}

\section{Results}

Figure 2 shows the total $\Delta \mathrm{v}$ requirement for each simulated launch vehicle configuration. As expected, velocity varies oppositely to launch mass for all propellant combinations. Considering the simplified assumptions used in the

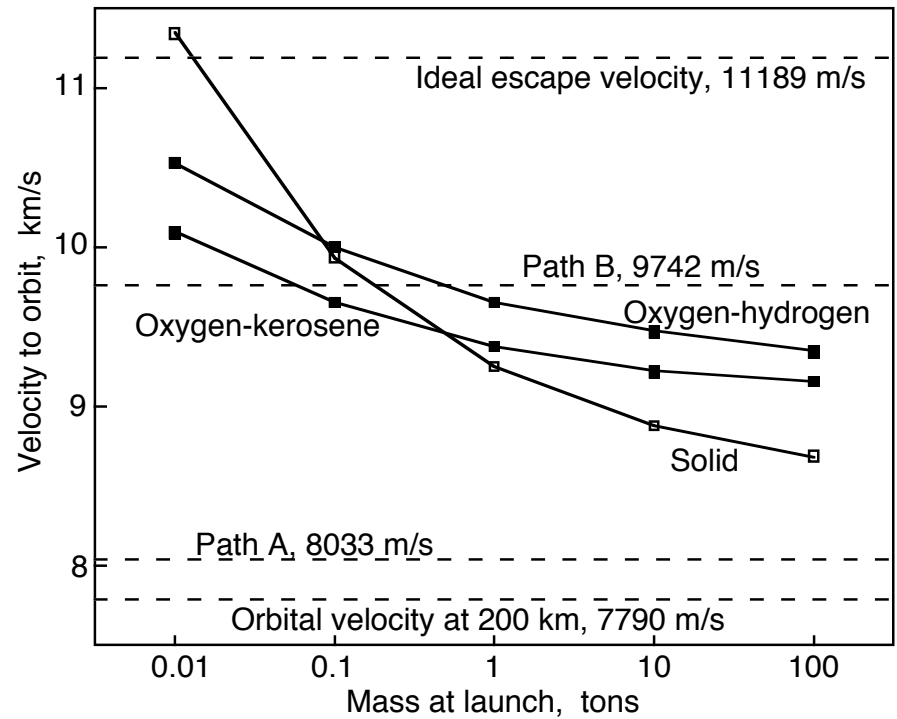

Fig. 2. Velocity requirements to a 200-km Earth orbit. calculations, the relative $\Delta v$ 's are more meaningful than the exact numbers. The graph shows that reaching orbit is somewhat more challenging for smaller vehicles. Comparisons from one propellant to another are more assumption-dependent than the effect of scaling for a given propellant option, but the general trends make sense.

Hydrogen's low density increases drag to contribute to higher $\Delta \mathrm{v}$ requirements than for kerosene. Secondly, gravity losses are higher for hydrogen since vehicle mass falls less rapidly at higher $\mathrm{I}_{\mathrm{SP}}$. Large solid rockets need less $\Delta \mathrm{v}$ because higher thrust reduces gravity losses, while scaling and density help to avoid extreme drag. However, the smallest solid rockets fare worse than the liquid options, because the scaling assumption results in excess thrust. 
The above insights are supported by the magnitudes of the circularization burns in Fig. 3, and the great circle arc angles, Fig. 4. The faster-accelerating solid rockets all reach $200 \mathrm{~km}$ closer to the launch site, with the need for large

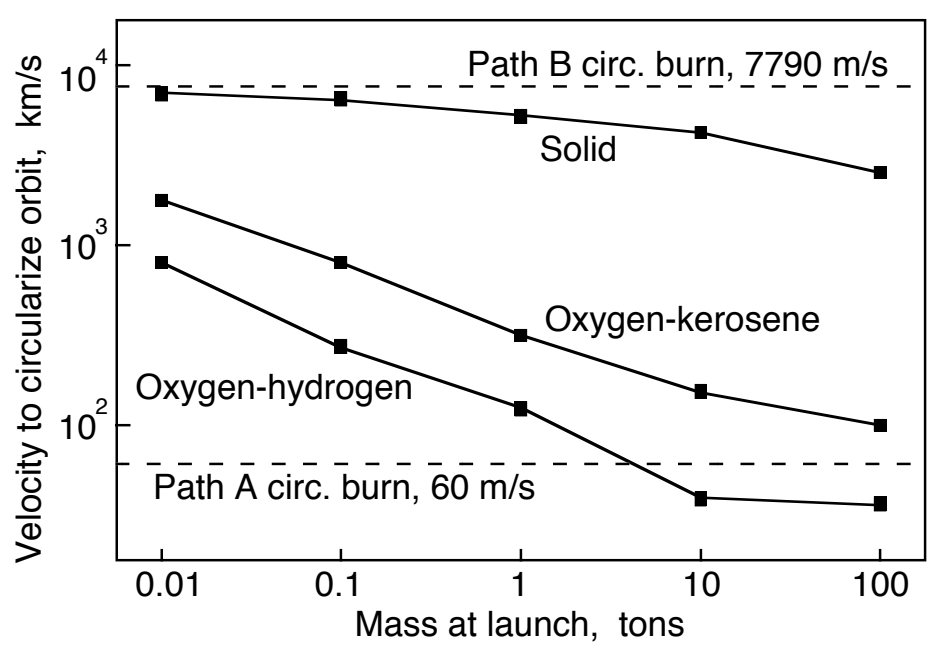

Fig. 3. Velocity to circularize orbits at $200 \mathrm{~km}$.

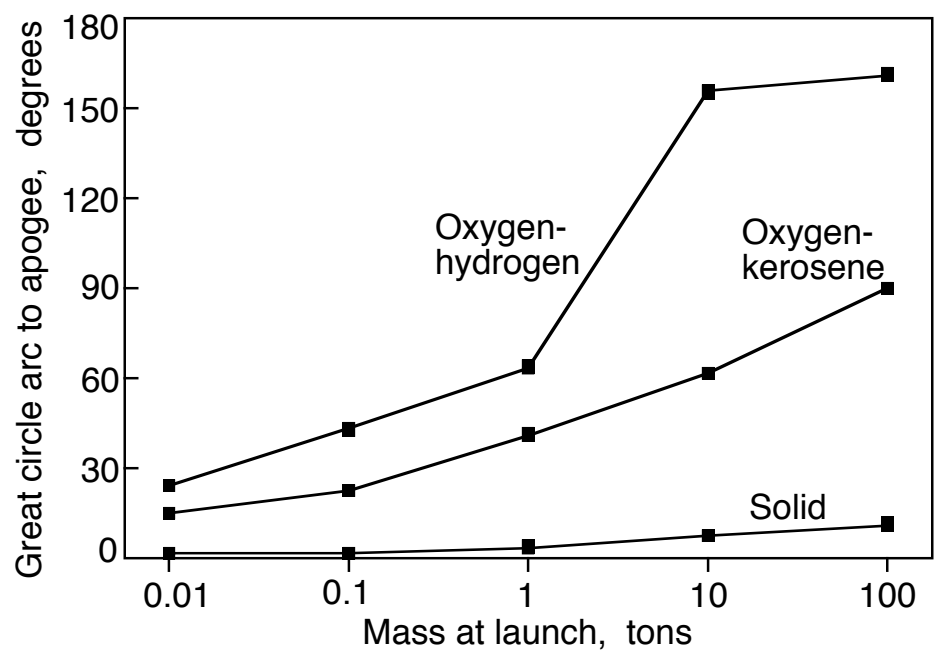

Fig. 4. Great circle arc angle at end point of ascent trajectories. orbit insertion burns. The large liquid vehicles follow trajectories that ultimately approach Path A. The extra $\Delta \mathrm{v}$ owed to low thrust can be called a gravity loss, since much of the propellant is consumed to react gravity rather than to accelerate the vehicle. Regardless of the thrust magnitude, the need for a nearly vertical launch, followed by almost horizontal thrusting, is inefficient for the same reason that Path $\mathrm{B}$ is.

Figure 3 shows two apogee burns smaller than that of Path A, indicating the large hydrogen-propelled vehicles arrive at $200 \mathrm{~km}$ along a trajectory that has a perigee above the Earth's surface. Fig. 4 shows a saturation effect for these two cases, because 180 degrees cannot be exceeded. Hydrogen's low rate of propellant consumption results in the least average acceleration. The associated long burn times (about $300 \mathrm{~s}$ ) permit the above-noted trajectory curvature toward Path A while still thrusting. For comparison, kerosene burn times were about $240 \mathrm{~s}$, and the solid thrust duration varied from $34 \mathrm{~s}$ to $98 \mathrm{~s}$ with increasing vehicle size.

The largest solid rockets have the least required $\Delta \mathrm{v}$ of all cases simulated, despite ascending relatively close to Path B. By way of explanation, even relatively small arc angles permit a significant horizontal velocity, e.g. $2 / 3$ of orbital velocity for the 100 -ton solid at only 12 degrees around the Earth. The distance from the launch site at 12 degrees is more than 6 times the altitude, i.e. the ascent is far from being vertical. In all the simulations having small circularization burns at large great circle positions, the total $\Delta \mathrm{v}$ was only weakly sensitive to changes in these two numbers.

Drag data in Table 3 indicates the effect of propellant density if the two liquid propellant combinations are compared. The dramatic effect of increased acceleration on drag may be appreciated by comparing the solid propellant column to the liquid cases. The largest

Table 3. Points of maximum atmospheric drag.

\begin{tabular}{|c|c|c|c|c|c|c|c|c|c|}
\hline \multirow{2}{*}{$\begin{array}{l}\text { Launch } \\
\text { mass, } \\
\text { tons }\end{array}$} & \multicolumn{3}{|c|}{ Oxygen-hydrogen (450 s) } & \multicolumn{3}{|c|}{ Oxygen-kerosene (350 s) } & \multicolumn{3}{|c|}{$\underline{\text { Solid }}(\mathrm{ISP}=280 \mathrm{~s})$} \\
\hline & $\begin{array}{l}\text { Peak } \\
\text { drag, kN }\end{array}$ & $\begin{array}{l}\text { Time, } \\
\text { s }\end{array}$ & $\begin{array}{l}\text { Altitude, } \\
\mathrm{km}\end{array}$ & $\begin{array}{l}\text { Peak } \\
\text { drag, kN }\end{array}$ & $\begin{array}{l}\text { Time, } \\
\mathrm{s}\end{array}$ & $\begin{array}{l}\text { Altitude, } \\
\mathrm{km}\end{array}$ & $\begin{array}{l}\text { Peak } \\
\text { drag, kN }\end{array}$ & $\begin{array}{l}\text { Time, } \\
\mathrm{s}\end{array}$ & $\begin{array}{l}\text { Altitude, } \\
\mathrm{km}\end{array}$ \\
\hline 0.01 & 0.044 & 132 & 22.7 & 0.043 & 104 & 18.0 & 0.37 & 14 & 4.3 \\
\hline 0.1 & 0.34 & 110 & 19.4 & 0.32 & 88 & 14.9 & 2.0 & 16 & 4.7 \\
\hline 1.0 & 2.5 & 94 & 16.3 & 2.1 & 78 & 12.6 & 9.5 & 20 & 5.1 \\
\hline 10 & 15 & 84 & 14.1 & 11 & 73 & 11.4 & 43 & 29 & 7.6 \\
\hline 100 & 85 & 80 & 13.0 & 58 & 71 & 10.8 & 170 & 32 & 6.4 \\
\hline
\end{tabular}


solid has only twice the peak drag of the hydrogen-propelled vehicle, while the smallest solid has almost an order of magnitude more than its liquid counterparts. The smaller solids reach their drag peaks sooner and lower than large solid rockets, owing to higher acceleration. In contrast, the liquid rockets all have the same thrust-to-mass ratios, so higher relative drag for the smaller ones reduces their actual acceleration (and velocity) enough that their drag peaks occur later and higher than for the large liquid-propelled vehicles. Note that the peak drag is one third of thrust for the smallest hydrogen case, but only one fifteenth of thrust at 100 tons.

The smallest solid has the highest acceleration of all cases studied, and its circularization burn in Fig. 4 is essentially that of the ideal Path B. Its extra total velocity in Fig. 2, relative to the Path B total, is attributable to drag. Table 3 shows that the $10-\mathrm{kg}$ solid vehicle's drag peak is nearly $60 \%$ of its thrust (Table 2 ).

\section{Discussion}

Overall, the results underscore the fact that atmospheric drag and finite thrust lead to complexities that are not evident from Fig. 1, although that diagram is helpful for understanding the problem.

Relevance of the simple non-staging model relies on the fact that most aerodynamic drag occurs relatively early, during what would be a first stage burn at liftoff thrust. The latest drag peak relative to ascent burn time occurs for the $10-\mathrm{kg}$ hydrogen case, after about $40 \%$ of the total $\Delta \mathrm{v}$ to orbit is applied.

An optimization of trajectories that includes steering, staging, and Earth rotation effects would doubtlessly yield different velocities from the simple model used here. The graphs should be interpreted mainly as approximations that indicate general trends and their rough magnitudes.

Launching from an aircraft at high altitude greatly reduces the significance of drag, which in general reduces the size of the smallest possible launch vehicle for any propellant choice. The smallest solid-propelled rockets would benefit the most from a high altitude start, while liquid propellants may be preferred for the smallest ground launches.

It should be cautioned that the trajectory results plotted say nothing about required propellant mass fractions or technology limits. In particular, the comparative velocities in Fig. 2 should not be interpreted as indicating the relative degree of difficulty when comparing propellant options. Considering the high ratio of area to mass on the smallest scales, non-cryogenic liquids might be appropriate. Hybrid propulsion may be of interest if the natural scaling effects offer appropriate thrust levels for desired vehicle sizes.

\section{Conclusion}

Trajectory considerations do not set a particular lower limit on launch vehicle size, but $\Delta \mathrm{v}$ requirements increase significantly. Achieving high propellant fractions on smaller scales is the main technical challenge, if the value of tiny payloads makes it worth doing. For example, launch vehicles smaller than 1 ton might deliver 1-kg satellites to orbit.

\section{Acknowledgment}

This work was performed under the auspices of the U.S. Department of Energy, by the University of California, Lawrence Livermore National Laboratory under Contract W-7405-Eng-48.

\section{References}

${ }^{1}$ Whitehead, J.C., "Trajectory Analysis and Staging Trades for Smaller Mars Ascent Vehicles,” J. Spacecraft, Accepted for publication, 2005. Revised from "Mars Ascent Propulsion Trades with Trajectory Analysis," AIAA Paper 2004-4069, July 2004. 